Article

\title{
Pre-Hydrated Berry Pomace in Wheat Bread: An Approach Considering Requisite Water in Fiber Enrichment
}

\author{
Anne-Marie Reißner* (D), Amanda Beer, Susanne Struck and Harald Rohm \\ Chair of Food Engineering, Technische Universität Dresden, 01062 Dresden, Germany; \\ amanda.beer@web.de (A.B.); susanne.struck@tu-dresden.de (S.S.); harald.rohm@tu-dresden.de (H.R.) \\ * Correspondence: anne-marie.reissner@tu-dresden.de; Tel.: +49-351-463-32420
}

Received: 30 September 2020; Accepted: 1 November 2020; Published: 3 November 2020

\begin{abstract}
Using blackcurrant pomace, for instance, in bread, prevents wasting this by-product of fruit juice production, thereby also taking advantage of its nutritional benefits. This study investigated the effects of blackcurrant pomace incorporation in wheat dough and the quality of the resulting breads. Two concepts were addressed: (a) adjusting the water level based on the dough consistency and (b) preparing pre-hydrated pomace by applying the determined water content prior to dough preparation and using it for bread making. Samples with wholegrain spelt flour were used for additional comparison. This study revealed that instant pomace incorporation with an adjusted water level diminished the dough stickiness and baking loss, but resulted in stiffer dough with delayed proofing and a decreased bread volume. The kneading resistance pointed to continued swelling after kneading, concomitant with a lower amount of available free water. Counteracting the competition for water of the flour components and pomace fiber by applying pre-hydrated pomace turned out to be successful. The deteriorating effects were reduced to a larger extent by pomace hydrated in hot water. Despite a similar composition, the products of wholegrain spelt flour deviated from the pomace formulations as well as from wheat breads (producing the highest water absorption but smallest loaves). As the water absorption of pomace fiber largely influences the product properties, a pre-hydration of pomace to be included in wheat dough can be highly recommended to enhance processing properties and product quality.
\end{abstract}

Keywords: pomace; dough; bread; water absorption; rheology; fiber; texture; sustainability; proofing

\section{Introduction}

The by-product of fruit juice processing contains valuable nutritional compounds that are lost when the pomace is disposed of. In addition to the dominating dietary fiber fraction mainly comprising pectin, hemicellulose, cellulose, and lignin, blackcurrant pomace contains considerable amounts of protein, fat, and polyphenols [1,2]. In line with the desire for a healthy and sustainable diet, incorporating this by-product in foods contributes to the enhancement of their nutritional and sensory properties [3]. However, the application in bakery products triggers a number of technological challenges.

In their review, Martins et al. [4] summarized that supplementing wheat bread with dietary fiber affects dough development time and stability, increases dough consistency, and therefore causes difficulties in processing. Bread rich in dietary fiber usually shows a reduced volume during baking and exhibits a firm, less cohesive crumb. Interactions between fiber and wheat protein as well as gluten dilution have been mentioned as the main reasons for these effects [4,5]. As regards soluble fiber, hydrocolloids such as hydroxypropylmethylcellulose, sodium alginate, or xanthan increased bread volume and crumb moisture at application levels even below 1\% [6], inulin improved gas retention up 
to $3 \%$ [7], and pectin and $\beta$-glucan at levels of $1 \%$ enhanced crumb structure without affecting sensory acceptability [8]. By contrast, as little as $2 \%$ of insoluble cellulose impaired dough extensibility and thus gas retention capacity and bread volume [9].

The high water-binding capacity of dietary fiber can be attributed to the large number of hydroxyl groups. In wheat dough, they compete with flour for water. This affinity potentially limits starch swelling and hence gelatinization [10]. In several studies, fruit pomace or isolated dietary fiber was incorporated in wheat dough without taking its high water-binding capacity into account. Only a few authors discussed the hydrating properties of the fiber and considered them during bread making $[7,11,12]$. Aiming at a similar dough consistency by adapting kneading resistance in farinograms [5] or by adjusting the storage modulus in rheological experiments through targeted water addition [13] turned out to be a successful way to improve the resulting product properties. However, to date, only short time scales after water addition, i.e., during kneading or after a resting period of $10 \mathrm{~min}[5,13]$, have been considered in analysis, while determining the water-binding capacity takes 30 min or longer.

In practice, bakeries usually apply seeds, grains, and groats in a pre-hydrated state. This swelling is performed in cold or hot water, and generally enhances water binding during processing. When hot water was used, enzyme activities were reduced in pre-hydrated grains [14].

Previously, we studied the interactions of berry pomace and wheat macromolecules in model dough systems, containing solely flour, pomace, and water [5]. It was hypothesized that pomace levels below $20 \%$ would produce bread with satisfying characteristics, but farinograms pointed to a prolonged dough development time and increased water absorption [5]. The aim of the current study was to systematically analyze the dough processibility and the properties of bread enriched with blackcurrant pomace that was subjected to pre-hydration at different conditions. Since mixtures of wheat flour with $10 \%$ blackcurrant pomace have similar contents of fiber, fat, and protein to wholegrain spelt flour, this common resource for fiber enrichment was included for additional comparison. The pomace used is a representative example of a fiber-rich, zero-waste by-product, and general indications for enrichment with other fibers may be derived from the results.

\section{Materials and Methods}

\subsection{Materials}

The ingredients used for bread making were demineralized water, all-purpose wheat flour type 550 (Dresdener Mühle, ZN der PMG Premium Mühlen Gruppe GmbH \& Co., Dresden, Germany), fresh yeast (Uniferm GmbH \& Co. KG, Werne, Germany), sodium chloride (Carl Roth GmbH \& Co. KG, Karlsruhe, Germany), and wholegrain spelt flour (Frießinger Mühle GmbH, Bad Wimpfen, Germany). Blackcurrant pomace (Döhler GmbH, Neuenkirchen Hadeln, Germany) was processed to a powder (volume-based median of particle size $\mathrm{x}_{50,3}=187.4 \pm 9.2 \mu \mathrm{m}$ ) by simultaneous drying and milling (Mahltechnik Görgens $\mathrm{GmbH}$, Dormagen, Germany) at a product temperature $<50{ }^{\circ} \mathrm{C}$. The water-binding capacity of the pomace powder was analyzed by adding a specified amount of water, hydrating for $30 \mathrm{~min}$, and decanting excess water after centrifugation [2], and is expressed as the amount of water bound per mass unit of dry pomace powder. The moisture content was determined by drying to a constant mass at $103^{\circ} \mathrm{C}$ for pomace powder and at $130^{\circ} \mathrm{C}$ for wheat flour according to ICC standard 110/1 [15]. The composition of the flours as specified by the suppliers, and of the blackcurrant pomace as previously published by Reißner et al. [2], is given in Table 1.

\subsection{Bread-Making Procedure}

The reference dough (Ref) consisted of $3 \mathrm{~g}$ of yeast and $1.5 \mathrm{~g}$ of $\mathrm{NaCl}$ dissolved in $56.5 \mathrm{~g}$ of deionized water per $100 \mathrm{~g}$ of wheat flour (corrected to $140 \mathrm{~g} / \mathrm{kg}$ of moisture). The wheat flour was partially replaced by $10 \%$ pomace powder (10P) or, for additional comparison and because wholegrain spelt (WS) flour shows a similar composition to 10P (Table 1), completely substituted with WS flour. 
To ensure controlled dough handling, the water content in each system was adjusted in preliminary experiments according to ICC standard 115/1 [16] with slight modifications, aiming at achieving a defined dough consistency of 600 Brabender Units (BU). Two modifications of 10P were prepared by pre-hydrating the pomace powder for $30 \mathrm{~min}$ in water at $20^{\circ} \mathrm{C}(10 \mathrm{Pc})$ or mixing with boiling water $(10 \mathrm{Ph})$, using the same amount of water as was determined by water absorption for 10P $(59.1 \mathrm{~g} / 100 \mathrm{~g}$ of flour). The 10Ph water reached room temperature during the soaking period, and the amount of water that evaporated was added before kneading.

Table 1. Dry matter-based proximate composition of raw materials.

\begin{tabular}{ccccc}
\hline $\begin{array}{c}\text { Component } \\
\mathbf{( g / 1 0 0 ~ g ) ~}\end{array}$ & $\begin{array}{c}\text { Blackcurrant } \\
\text { Pomace }^{\mathbf{1}}\end{array}$ & $\begin{array}{c}\text { Wheat } \\
\text { Flour }\end{array}$ & $\begin{array}{c}\mathbf{9 0 \%} \text { Wheat Flour } \\
\mathbf{+ 1 0 \%} \text { Pomace }\end{array}$ & $\begin{array}{c}\text { Wholegrain } \\
\text { Spelt Flour }\end{array}$ \\
\hline Carbohydrates & 2.2 & 81.2 & 73.3 & 70.4 \\
Dietary fiber & 59.1 & 2.7 & 8.3 & 9.3 \\
Protein & 15.7 & 15.1 & 15.1 & 15.7 \\
Fat & 20.2 & 0.9 & 2.9 & 2.1 \\
Ash & 2.7 & 0.7 & 0.9 & 0.9 \\
\hline \multicolumn{5}{r}{}
\end{tabular}

${ }^{1}$ Data from Reißner et al. [2].

Dough was prepared in a $300 \mathrm{~g}$ farinograph cell at $26^{\circ} \mathrm{C}$ (Brabender $\mathrm{GmbH} \& \mathrm{Co} . \mathrm{KG}$, Duisburg, Germany), first blending the flour (Ref) or the dry flour/pomace mixture (10P) for $1 \mathrm{~min}$ at $63 \mathrm{rpm}$. After adding the remaining ingredients (including the pre-hydrated pomace for $10 \mathrm{Pc}$ or $10 \mathrm{Ph}$ ), the dough was kneaded for $4 \mathrm{~min}$. During pre-proofing at $26^{\circ} \mathrm{C}$, the dough was kneaded after 15 and $30 \mathrm{~min}$ for $15 \mathrm{~s}$ at $63 \mathrm{rpm}$, subsequently shaped into pieces of $100 \mathrm{~g}$, and evenly perforated with a pin roller. After $35 \mathrm{~min}$ of main proofing in a proofing chamber $\left(32{ }^{\circ} \mathrm{C}, 80 \%\right.$ relative humidity), the bread was baked for $20 \mathrm{~min}$ at $240{ }^{\circ} \mathrm{C}$ (MIWE Condo, Michael Wenz GmbH, Arnstein, Germany). The loaves were allowed to cool for $30 \mathrm{~min}$ at $20^{\circ} \mathrm{C}$ in a Peltier-cooled IPP-55 incubator (Memmert GmbH \& Co. KG, Schwabach, Germany), packed in polyethylene bags, and analyzed within $3 \mathrm{~h}$. Two independent batches of 4 loaves were produced for each formulation.

\subsection{Dough Analysis}

Expansion during the main proofing of $30 \mathrm{~g}$ of shaped dough (formulations: Ref, 10P, 10Pc, and $10 \mathrm{Ph}$ ) was monitored in graduated cylinders over a period of $60 \mathrm{~min}$ at $32{ }^{\circ} \mathrm{C}$ and $80 \%$ humidity $(n=2)$. Changes in volume were plotted against the proofing time and fitted by cubic equations.

The $\mathrm{pH}$ was measured immediately after dough preparation by means of a $\mathrm{pH}$ meter (Knick Elektronische Messgeräte GmbH \& Co. KG, Berlin, Germany) with a puncture electrode for viscoelastic samples (BlueLine, Xyleme Analytics Sales GmbH \& Co. KG, Germany), in triplicate $(n=6)$.

The dough resistance and extensibility were determined using a TA.XTplus Texture Analyzer (Stable Micro Systems Ltd., Godalming, UK) and a Kieffer dough extensibility rig by following the procedure described by Verheyen et al. [17]. Immediately after preparation, $20 \mathrm{~g}$ of dough was round shaped, formed into strands with the aid of an oiled Teflon sample plate, and allowed to rest for $10 \mathrm{~min}$ at $32{ }^{\circ} \mathrm{C}$. Five strands of each dough ( $n=10$ replicates per formulation) were extended with a rig velocity of $3.3 \mathrm{~mm} / \mathrm{s}$ until tearing. The maximum force refers to the dough resistance, and the travelling distance of the rig until tearing is defined as the extensibility. To account for time-dependent effects, additional measurements were performed after pre-proofing (30 $\mathrm{min}$ ) and main proofing ( $65 \mathrm{~min}$ of total proofing time). The respective dough samples were kneaded twice as in the bread-making procedure (i.e., after 15 and $30 \mathrm{~min}$ ).

Dough stickiness was defined as the maximum tensile force when removing a cylindrical probe from a defined dough surface. The measurements were performed using a Chen-Hoseney cell mounted on the TA.XTplus Texture Analyzer as described by Struck et al. [5]. Ten measurements per dough $(n=20)$ were recorded after 75 min of main proofing, as the dough stickiness, when hydration processes are considered as being complete, is usually independent of the fermentation time [18]. 
For small strain oscillation rheology, dough with an identical formulation was prepared separately without yeast. Dough with wholegrain spelt was, due to its stickiness, excluded from the rheological experiments. A dough sample of $8.5 \mathrm{~g}$ was rolled out and placed on the lower plate of a Physica MCR 300 rheometer (Anton Paar GmbH, Graz, Austria). A 50 mm-diameter serrated upper plate was lowered until a gap of $2 \mathrm{~mm}$ was reached. Prior to measurements, excess material was trimmed, the gap was covered with Vaseline oil, and the sample was allowed to relax in the gap for $5 \mathrm{~min}$ at $25{ }^{\circ} \mathrm{C}$. The measurement regime comprised of a frequency sweep from 10 to $0.1 \mathrm{~Hz}$ in the linear viscoelastic region at a strain of $0.3 \%$ (10 points per decade) at $25^{\circ} \mathrm{C}$, followed by a temperature sweep up to $100{ }^{\circ} \mathrm{C}$ at $6.3 \mathrm{~K} / \mathrm{min}$, representing the heating rate during oven baking, and a frequency of $1 \mathrm{~Hz}$. The storage modulus $\left(\mathrm{G}^{\prime}\right)$ and loss modulus $\left(\mathrm{G}^{\prime \prime}\right)$ were derived from the measurements. The complex modulus $G^{*}$ is the Pythagorean sum of $G^{\prime}$ and $G^{\prime \prime}$ and refers to the overall resistance to deformation and, hence, stiffness of the dough. The loss tangent $\left(\tan \delta=G^{\prime \prime} / G^{\prime}\right)$ indicates whether elastic or viscous contributions are dominating. All the measurements were performed on two individually prepared doughs $(n=2)$.

\subsection{Bread Analysis}

The relative baking loss was calculated from mass difference of 8 loaves before and after baking. The bread volume was determined using the canola seed method 10-05.01 [19]. The $\mathrm{pH}$ of the crumb was measured with a puncture electrode (two breads in duplicate) as described for dough.

The crust firmness was determined with the TA.XTplus Texture Analyzer by penetrating the surfaces of 4 loaves at 8 individual points with a cylinder of $4 \mathrm{~mm}$ diameter at a testing speed of $40 \mathrm{~mm} / \mathrm{s}$. The maximum force was defined as the crust firmness $(n=32)$. The breads were then cut into $12.5 \mathrm{~mm}$-thick slices, and the crumb firmness of two stacked central slices was measured by compression with a cylinder of $25 \mathrm{~mm}$ diameter. In line with approved method 74-09.01 [20], the testing speed was $1 \mathrm{~mm} / \mathrm{s}$ and the final compression was $40 \%$. The compression force at $6.25 \mathrm{~mm}$ ( $25 \%$ compression) was defined as the crumb firmness. Two slices of four breads were analyzed in quadruplicate $(n=32)$.

For analyzing the crumb structure, eight bread slices were scanned with a CanoScan Lide 110 (Canon Germany GmbH, Krefeld, Germany) at a resolution of 600 dpi. Using the Image software (National Institutes Health, Bethesda, MD, USA), the images were converted to 8-bit grayscale, cropped to $30 \times 30 \mathrm{~mm}^{2}$, and binarized by applying the Otsu threshold algorithm. Cell counts and respective cell areas $\left(\mathrm{mm}^{2}\right)$ were determined, and the cell density $\left(\mathrm{cells} / \mathrm{cm}^{2}\right)$ and total cell area $\left(\mathrm{mm}^{2} / 100 \mathrm{~mm}^{2}\right)$ were calculated.

For the following analyses, $100 \mathrm{~g}$ of crumb (representative sample of 2 breads per batch) was comminuted for $10 \mathrm{~s}$ at $5000 \mathrm{rpm}$ in a Grindomix GM200 mill (Retsch GmbH, Haan, Germany). The crumb moisture $(n=6)$ was determined at $105^{\circ} \mathrm{C}$ in a MA30 moisture analyzer (Sartorius AG, Göttingen, Germany). The color was measured with a Luci 100 spectral colorimeter (D65 xenon lamp, $10^{\circ}$ observer; Hach Lange $\mathrm{GmbH}$, Düsseldorf, Germany) after compressing $2 \mathrm{~g}$ of powdered crumb with a $32 \mathrm{~mm}$ acryl plunger in a Quartz glass cylinder $(\mathrm{d}=34 \mathrm{~mm})$. The color primaries of quadruplicate measurements were transferred into the CIE-Lab color space, and the lightness $L^{*}$, hue angle $h_{a b}$ (describing the color quality), and chroma $\mathrm{C}^{*}$ (indicating saturation) were calculated for interpretation [21].

\subsection{Statistical Analysis}

Analysis of variance (ANOVA) with subsequent Student-Newman-Keuls and Duncan post hoc testing at $p \leq 0.05$ ( $p \leq 0.1$ for crumb firmness), and regression analyses were performed with SAS University Edition 6p.2 (SAS Institute Inc., Cary, NC, USA). Before analysis, biological and technical replicates were pooled. 


\section{Results and Discussion}

\subsection{Hydration Properties}

The amount of water necessary to achieve $600 \mathrm{BU}$ in the reference dough was $56.5 \mathrm{~mL}$ per $100 \mathrm{~g}$ of wheat flour. This amount increased by $4.6 \%$ to $59.1 \mathrm{~mL} / 100 \mathrm{~g}$ for $10 \mathrm{P}(10 \%$ of the wheat flour replaced by blackcurrant pomace), reflecting its higher water affinity. The dough prepared from wholegrain spelt flour absorbed even more water $(67.1 \mathrm{~mL} / 100 \mathrm{~g})$. Frakolaki et al. [22] attributed this water affinity in farinograms to a higher protein content compared to wheat flour, which is also true for berry pomace. The high dietary fiber content in wholegrain flour is another factor that influences water absorption.

After 4 min of kneading, the resistance of the Ref dough was $621 \pm 14$ BU. As reported previously [5], the incorporation of dry pomace prolonged dough development but resulted in a similar dough resistance after an identical kneading time (605 $\pm 5 \mathrm{BU})$. On the other hand, dough containing pre-hydrated pomace showed a significantly higher resistance of $712 \pm 12$ and $691 \pm 30$ BU for 10Pc and $10 \mathrm{Ph}$, respectively. This phenomenon emphasizes the time-dependent process of hydration: dietary fiber and starch granules soaked up water beyond the 4 min kneading time; hence, prolonged hydration periods seem to be reasonable. This means that pre-hydration could be beneficial for dough formation, whereas extending kneading time probably results in a damaged gluten structure. The WS dough showed an intermediate kneading resistance $(645 \pm 1 \mathrm{BU})$, less pronounced than that for pre-hydrated pomace dough, and, concomitantly, prolonged dough development.

The dry matter-related water-binding capacity of the blackcurrant pomace powder was $4.46 \mathrm{~g} / \mathrm{g}$ at room temperature $\left(20^{\circ} \mathrm{C}\right)$ and increased to $5.70 \mathrm{~g} / \mathrm{g}$ after hydrating the pomace in boiling water. This can be attributed to the denaturation of pomace proteins and to the gelation of water-soluble pectins after cooling, which still make up 10\% in enzymatically treated blackcurrant pomace [1]. In light of the increased kneading resistance and water binding capacity for $10 \mathrm{Ph}$, even more water for dough preparation may be feasible, but that would require a different methodology. It should further be noted that such an adaption may directly affect dough and bread properties.

\subsection{Rheology during Simulated Baking}

Small-amplitude oscillation rheology provided further insights into the effects of pomace incorporation. Figure 1 depicts the complex modulus $\left(\mathrm{G}^{*}\right)$ and the loss tangent $(\tan \delta)$ as observed in frequency sweeps at $25{ }^{\circ} \mathrm{C}$, and in subsequent temperature sweeps. All the doughs showed predominantly elastic behavior $(\tan \delta<1)$.

At $25{ }^{\circ} \mathrm{C}$, the dough stiffness increased with increasing frequency, with a power law slope of $\approx 0.2$, thus pointing to shear-thinning behavior. Compared to Ref, the addition of $10 \%$ pomace resulted in much stiffer doughs. This stiffening indicates that cross-linking between pomace compounds and wheat proteins occurs, and that less free water is available in the dough [23]. As compared to 10P, 10Pc did not show a significant impact on dough rheology, but $10 \mathrm{Ph}$ shifted $\mathrm{G}^{*}$ towards Ref. The between-dough differences in tan $\delta$ were mainly caused by differences in the storage modulus, as the loss moduli were almost similar. It can be assumed that the interactions of dietary fiber with wheat proteins remained unchanged, but denatured pomace proteins released bound water and increased molecular mobility. Alba et al. [10] analyzed the rheology of wheat dough with blackcurrant pomace and its insoluble dietary fiber fractions (5-20\%) without adjusting the water level in formulations, and attributed the observed stiffening to higher cellulose contents. This effect became more prominent at higher pomace fractions.

During baking simulated in temperature sweeps, three stages can be distinguished. Through heating, $\mathrm{G}^{*}$ reached a minimum in the first stage, and was the lowest for Ref (5 kPa) and approx. three times higher for $10 \mathrm{P}(14 \mathrm{kPa})$. The differences in the temperature at this minimum $\left(52.6-55.2^{\circ} \mathrm{C}\right.$ ) were not significant. The reduced stiffness can be explained by thermally activated molecules, a softened protein structure, and melting of the fat [13]. Further heating induced starch swelling, gelatinization, and protein denaturation [13], leading to reduced molecular mobility. The tan 
$\delta$ started to drop at $73{ }^{\circ} \mathrm{C}$, representing the onset of major structural changes, evident from increased elastic contributions. The maximum stiffnesses were 94 and $144 \mathrm{kPa}$ for Ref and 10P, respectively. The $10 \mathrm{Ph}(112 \mathrm{kPa})$ dough was similar to Ref, indicating continuing effects of the previous swelling on the dough stiffness. The corresponding temperature at the maximum $\mathrm{G}^{*}$ tended to decrease in the order Ref, 10P, $10 \mathrm{Pc}$, and $10 \mathrm{Ph}\left(87.3-84.0^{\circ} \mathrm{C}\right)$, pointing to reduced water competition with starch granules when hydrated pomace was incorporated. In contrast to the findings of Alba et al. [10], the gelation temperature was not affected by pomace application. The reduced starch content of the pomace-containing dough was reflected by a less pronounced magnitude of changes in stiffness between the minimum $G^{*}$ and maximum $G^{*}$ [24].
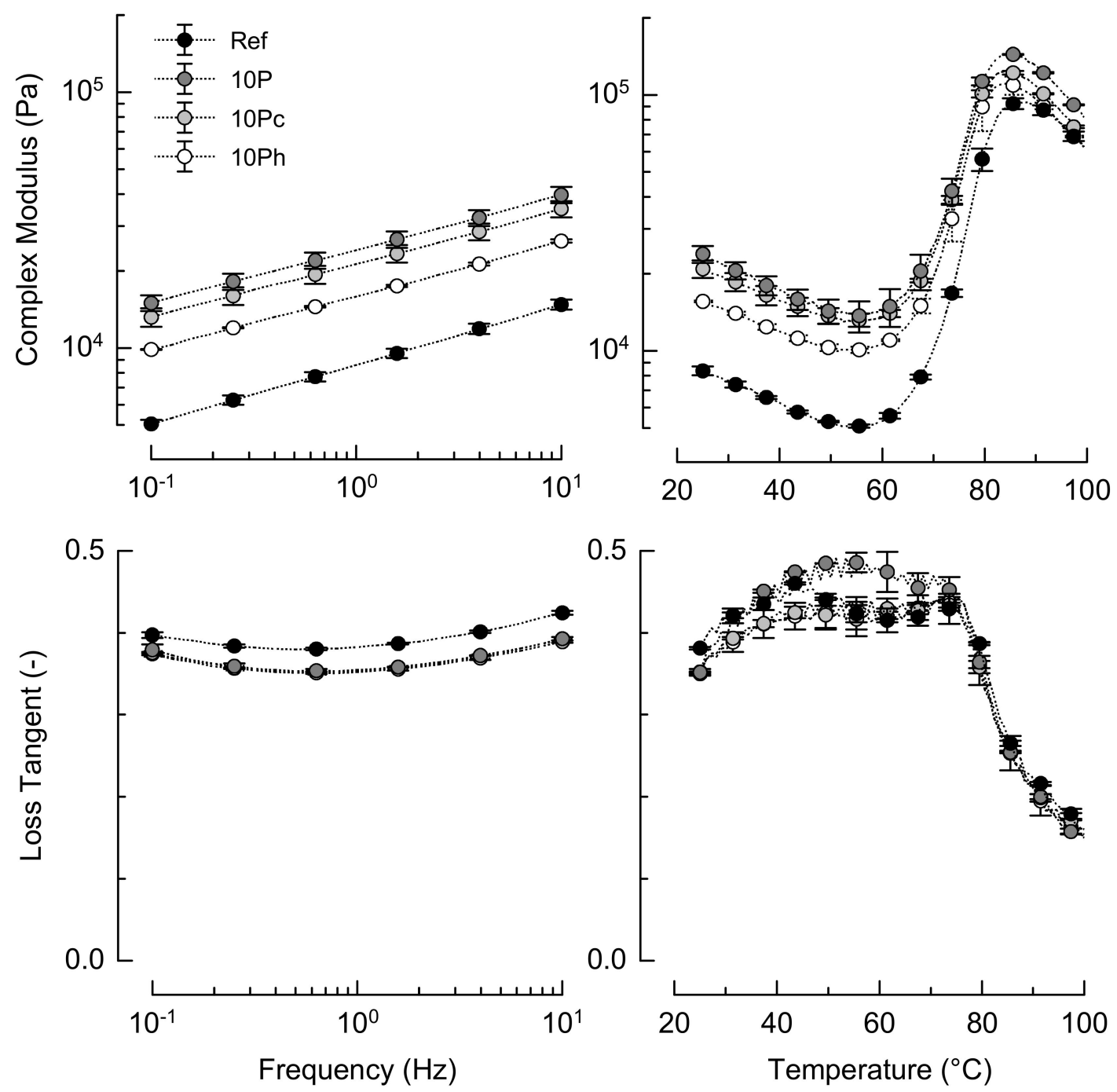

Figure 1. Frequency dependency of dough stiffness and the loss tangent at $25^{\circ} \mathrm{C}$ (left), and development of stiffness and loss tangent during simulated baking (right) $(n=2)$. Ref, reference dough; 10P, dough based on $90 \%$ wheat flour and $10 \%$ pomace; $10 \mathrm{Pc}$, similar to $10 \mathrm{P}$ but with pomace soaked in cold water; $10 \mathrm{Ph}$, similar to $10 \mathrm{P}$ but with pomace soaked in boiling water. To improve clarity, not all data points are plotted.

\subsection{Changes in Dough Properties during Proofing}

The increase in dough volume during the main proofing, starting at $30 \mathrm{~min}$ after kneading, is depicted in Figure 2. The curves were fitted by cubic equations, achieving reliable coefficients of determination $\mathrm{R}^{2}>0.99$. 


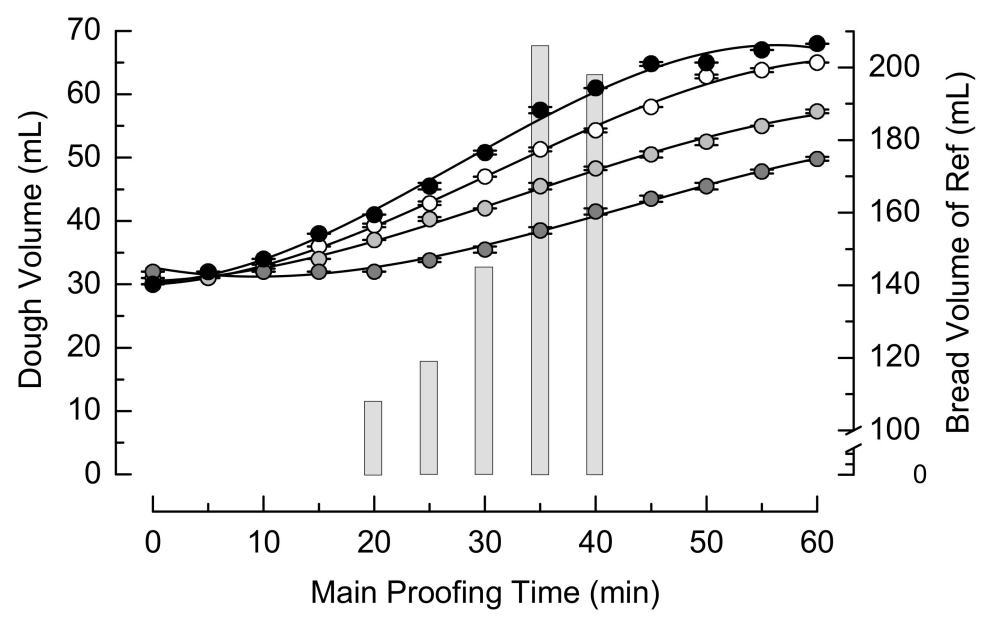

Dough volume $(\mathrm{mL})=$

$$
\begin{aligned}
& -0.0004 \frac{\mathrm{mL}}{\min ^{3}} * \min ^{3}+0.033 \frac{\mathrm{mL}}{\min ^{2}} * \min ^{2}+0.07 \frac{\mathrm{mL}}{\min } * \min +30.3 \mathrm{~mL} \text { - Ref } \\
& -0.0002 \frac{\mathrm{mL}}{\min ^{3}} * \min ^{3}+0.019 \frac{\mathrm{mL}}{\min ^{2}} * \min ^{2}-0.31 \frac{\mathrm{mL}}{\min } * \mathrm{~min}+32.6 \mathrm{~mL} \text { - } 10 \mathrm{P} \\
& -0.0002 \frac{\mathrm{mL}}{\min ^{3}} * \min ^{3}+0.015 \frac{\mathrm{mL}}{\min ^{2}} * \min ^{2}+0.07 \frac{\mathrm{mL}}{\min } * \min +30.5 \mathrm{~mL} \nsubseteq 10 \mathrm{Pc} \\
& -0.0003 \frac{\mathrm{mL}}{\min ^{3}} * \min ^{3}+0.024 \frac{\mathrm{mL}}{\min ^{2}} * \min ^{2}+0.08 \frac{\mathrm{mL}}{\min } * \min +30.0 \mathrm{~mL}-10 \mathrm{Ph}
\end{aligned}
$$

Figure 2. Increase in dough volume during main proofing (symbols and curves, $n=2$ ) and volume of the reference bread baked after different main proofing periods (bars, $n=4)$. Ref, reference dough; 10P, dough based on $90 \%$ wheat flour and $10 \%$ pomace; $10 \mathrm{Pc}$, similar to $10 \mathrm{P}$ but with pomace soaked in cold water; $10 \mathrm{Ph}$, similar to $10 \mathrm{P}$ but with pomace soaked in boiling water.

After an initial phase of approx. $10 \mathrm{~min}$, the volume increased steadily. The quadratic coefficient indicates the highest rise for Ref and $10 \mathrm{Ph}$, but the slope declined in the final stage of proofing. To identify effects on bread volume, the Ref dough was baked after different proofing times. The highest bread volume was observed after $35 \mathrm{~min}$ of main proofing, and this time was therefore chosen as the proofing time in all other baking experiments (i.e., a total fermentation time of $65 \mathrm{~min}$ ). Comparing with the increase in dough volume, this optimized bread volume was reached after the inflection point of the respective cubic function ( $27 \mathrm{~min}$ ) but before the dough volume curve flattened out. Sample 10P showed a delayed and impaired increase in volume, and the inflection point was shifted to $31 \mathrm{~min}$. Pre-hydrated pomace in the dough attenuated this deteriorated proofing behavior, $10 \mathrm{Ph}$ to a larger extent than 10Pc.

Figure 3 shows the dough resistance and extensibility as affected by the proofing time. The resistance increased within $30 \mathrm{~min}$ after kneading, pointing to continuing structure formation. During the main rise, up to $65 \mathrm{~min}$ of total proofing time, enzyme activity is responsible for partial gluten degradation and stress relaxation [17], so the dough resistance significantly decreased. As opposed to Ref, 10P resulted in doughs with higher resistance after proofing for 30 and $65 \mathrm{~min}$, presumably because of interactions between dietary fiber, wheat or pomace proteins, and polysaccharides [25,26]. This is also consistent with the increased stiffness in the frequency sweeps at $25^{\circ} \mathrm{C}$ (Figure 1). Both pre-hydrated samples differed significantly from 10P. Whereas 10Pc showed a similar resistance to Ref, $10 \mathrm{Ph}$ exhibited a much higher resistance after pre-proofing. The dough resistance finally dropped after $65 \mathrm{~min}$ to $0.42 \pm 0.05 \mathrm{~N}$, which is lower than that of 10P. This behavior is caused by (a) the effects of protein denaturation caused by pre-hydrating pomace in boiling water, and (b) the available water that favored gluten relaxation. The dough resistance in WS increased continuously up to $65 \mathrm{~min}$ of proofing time. The higher gliadin levels in the wholegrain spelt flour retarded a tension drop [22], and firmer doughs were obtained after fermentation. However, WS showed the lowest dough resistance among all formulations. 

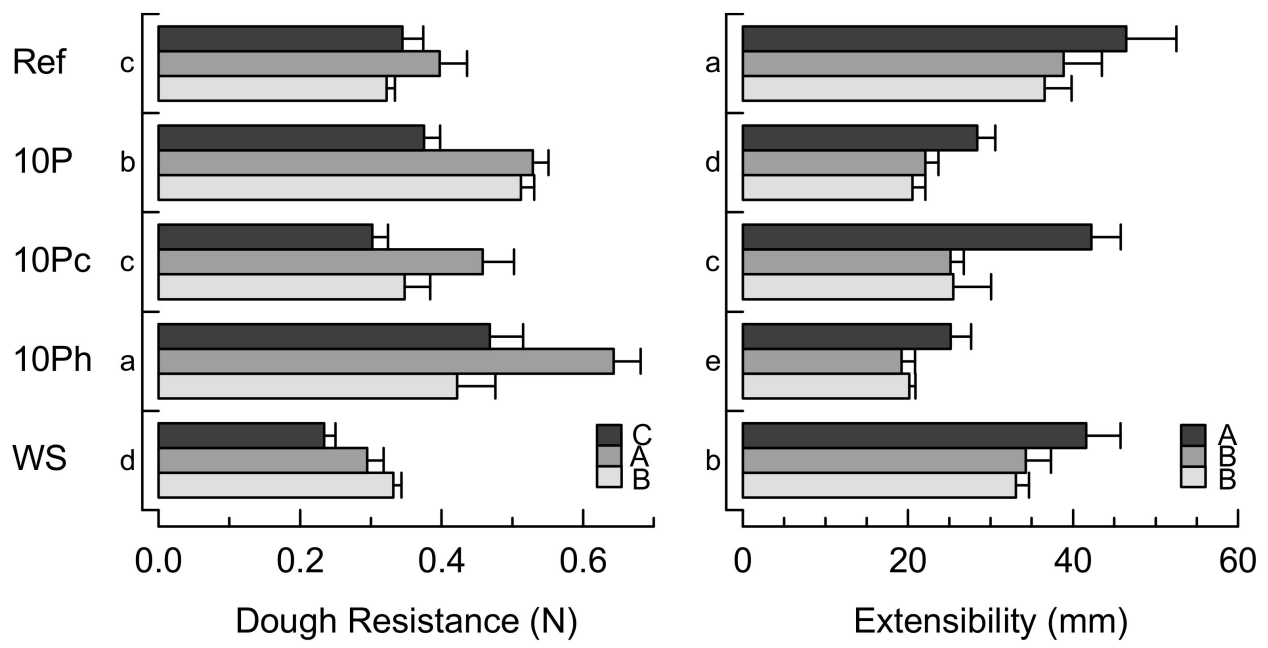

Figure 3. Dough resistance (left) and extensibility (right) of dough after different periods of proofing: dark gray, immediately after kneading; gray, after 30 min pre-proofing; light grey, after $30 \mathrm{~min}$ pre-proofing + 35 min main proofing. Ref, reference dough; 10P, dough based on $90 \%$ wheat flour and $10 \%$ pomace; $10 \mathrm{Pc}$, similar to $10 \mathrm{P}$ but with pomace soaked in cold water; $10 \mathrm{Ph}$, similar to $10 \mathrm{P}$ but with pomace soaked in boiling water; WS, wholegrain spelt flour dough. Lowercase letters indicate significant differences $(p<0.05)$ among formulations; uppercase letters indicate significant differences $(p<0.05)$ among proofing times.

The extensibility was the highest for all the doughs immediately after kneading and decreased with proofing time (Figure 3). The reference showed the highest extensibility, followed by WS, indicating a strong gluten network [27]. Pomace application generally decreased the extensibility, which can be attributed to fiber enrichment; a restricted molecular mobility through the formation of fiber/protein interactions, such as hydrogen bonds; and the dilution of the gluten network $[5,27]$. Nevertheless, immediately after kneading, the extensibility of 10Pc was comparable to that of Ref. Compared to dough resistance, it was observed that the higher extensibility in the pomace-containing dough was accompanied by a decreased resistance. Therefore, the low resistance in extension is presumably attributable to a weakened gluten structure that could affect bread volume [28].

The dough stickiness, reflecting free surface water, is displayed in Table 2. The highest stickiness was observed for Ref and WS. When handling WS, its stickiness appeared to be much higher than any other dough, which was not reflected by the measurements but can be attributed to the gliadin proteins [22]. Although the pomace dough contained more water than Ref, its water-binding capacity compensated the stickiness, which decreased significantly.

The impact of pomace pre-hydration turned out to be negligible. The acidity of the blackcurrant pomace, expressed as tartaric acid equivalent, was reported to be $4.5 \mathrm{~g} / \mathrm{kg}$ [2]. Therefore, the dough $\mathrm{pH}$ dropped when pomace was added, namely, from 5.77 (Ref) to 5.11 (10P). As the reasonable $\mathrm{pH}$ for yeast fermentation ranges from 4.5 to 6.0 [29], negative effects on bread quality should not be expected.

Table 2. Dough and bread characteristics.

\begin{tabular}{|c|c|c|c|c|c|c|}
\hline Sample ${ }^{1}$ & $\begin{array}{l}\text { Dough Stickiness } \\
\text { (N) }(n=20)^{2}\end{array}$ & $\begin{array}{l}\text { Dough pH (-) } \\
\quad(n=6)^{2}\end{array}$ & $\begin{array}{l}\text { Bread pH (-) } \\
\quad(n=4)^{2}\end{array}$ & $\begin{array}{l}\text { Baking Loss } \\
(\%)(n=8)^{2}\end{array}$ & $\begin{array}{l}\text { Bread Volume } \\
(\mathrm{mL})(n=8)^{2}\end{array}$ & $\begin{array}{l}\text { Crumb Moisture } \\
(\mathrm{g} / 100 \mathrm{~g})(n=6)^{2}\end{array}$ \\
\hline Ref & $0.49 \pm 0.03^{a}$ & $5.77 \pm 0.01^{\mathrm{a}}$ & $5.90 \pm 0.01^{\mathrm{a}}$ & $15.59 \pm 0.38^{b}$ & $181.83 \pm 4.50^{\mathrm{a}}$ & $41.41 \pm 0.15^{\mathrm{d}}$ \\
\hline $10 \mathrm{Pc}$ & $0.35 \pm 0.04^{b}$ & $5.15 \pm 0.01^{c}$ & $5.01 \pm 0.01^{\mathrm{c}}$ & $14.61 \pm 0.36^{c}$ & $163.45 \pm 2.33^{c}$ & $42.09 \pm 0.19^{b}$ \\
\hline $10 \mathrm{Ph}$ & $0.32 \pm 0.05^{b}$ & $5.15 \pm 0.01^{c}$ & $5.01 \pm 0.01^{\mathrm{c}}$ & $14.10 \pm 0.28^{\mathrm{d}}$ & $171.71 \pm 7.89^{b}$ & $42.78 \pm 0.11^{a}$ \\
\hline WS & $0.50 \pm 0.05^{\mathrm{a}}$ & $5.74 \pm 0.01^{b}$ & $5.72 \pm 0.01^{b}$ & $17.45 \pm 0.24^{\mathrm{a}}$ & $141.25 \pm 0.45^{\mathrm{d}}$ & $42.85 \pm 0.09^{a}$ \\
\hline
\end{tabular}

${ }^{1}$ Ref, reference dough/bread; $10 \mathrm{P}$, dough/bread based on $90 \%$ wheat flour and $10 \%$ pomace; $10 \mathrm{Pc}$, similar to $10 \mathrm{P}$ but with pomace soaked in cold water; 10Ph, similar to 10P but with pomace soaked in boiling water; WS, dough/bread of wholegrain spelt flour. ${ }^{2}$ Mean values ( \pm standard deviation) in a column with different superscripts differ significantly $(p<0.05)$. 


\subsection{Effects on Bread Characteristics}

Chemical processes and water evaporation during baking reduced the acidity of the Ref bread crumb to $\mathrm{pH}$ 5.9. The typical acidity of wheat bread varies in the range of $\mathrm{pH}$ 5.2-6.0 [30]. By contrast, the acidity of the pomace dough increased through baking to approx. $\mathrm{pH}$ 5.0, due to altered water binding, which increased organic acids in the free water phase.

In terms of staling, using pomace could be beneficial, since losing moisture during storage could be counteracted through the elevated water-binding capacity of the fiber [31,32]. This presumption is supported by the reduced baking loss and enhanced crumb moisture (Table 2) in the pomace-containing bread. Pre-hydrated pomace affected water retention during the baking process, and $10 \mathrm{Ph}$ increased the crumb moisture to an even greater extent than 10Pc. It can be assumed that the hydrated fiber and pomace protein compete less for water with the flour components when previously heated. Furthermore, the reduced gas retention ability of 10Pc may have caused an additional moisture loss. WS lost more water during baking, since the crumb moisture was identical to 10Ph's despite the highest water absorption of the wholegrain spelt flour during kneading.

When containing blackcurrant pomace, the bread volume decreased from $181.8 \mathrm{~mL}$ (Ref) to $162.2 \mathrm{~mL}$ (10P). WS resulted in even smaller loaves, as the baking loss was high and the baking properties of its gluten composition were different [22]. As opposed to $10 \mathrm{P}, 10 \mathrm{Ph}$ substantially increased bread volume, while 10Pc had negligible effects. Various studies have reported detrimental effects on bread quality from applying pomace or isolated fiber fractions $[10,33,34]$. The causes were attributed to diluted gluten and protein/fiber interactions [5,34]. However, appropriate amounts of soluble fiber [33] and, as shown in this study, adjusting the water content based on dough stiffness are helpful for minimizing undesired effects.

The crust and crumb firmness as influenced by wheat flour replacement is shown in Table 3. The main differences were apparent for WS, which solidified the bread structure. The 10P produced marginal changes compared to Ref; only the crumb firmness of 10Pc tended to be reduced compared to $10 \mathrm{Ph}$. Other studies reported softer crumbs when applying up to $30 \%$ grape pomace [12], $20 \%$ wheat bran [11], or 3\% pea or carob fiber [7] while taking the water absorption of the fiber into account.

As regards the bread structure parameters, supporting the texture data, Ref showed the lowest cell density and total cell area $\left(26\right.$ cells $\left./ \mathrm{cm}^{2} ; 26 \mathrm{~mm}^{2} / 100 \mathrm{~mm}^{2}\right)$ (Table 3$)$. For WS, the proportion of cells on the total area was increased $\left(33 \mathrm{~mm}^{2} / 100 \mathrm{~mm}^{2}\right)$, indicating a less compact structure with extended pores. A weakened gluten structure with a low gas holding capacity manifests in the aggregation of small cells into a few larger cells [14,35]. Alba et al. [10] reported a reduced cell number and cell area accompanied with a denser crumb for bread with $10 \%$ blackcurrant pomace. In this study, the cell density and total area of the pomace breads increased concurrently, contradicting crumb defects. The softened crumb of 10Pc showed the highest total cell area $\left(38 \mathrm{~mm}^{2} / 100 \mathrm{~mm}^{2}\right)$. According to Holmes and Hoseney [36], the dough $\mathrm{pH}$ affects the gas production rate of the yeasts and correlates with the final bread volume and crumb grain. In this study, both the dough and bread $\mathrm{pH}$ correlated negatively with crumb cell density $(r \approx-0.97)$ but were not linked to the volume. In detail, a lower $\mathrm{pH}$ tended to slow down yeast activity, and smaller cells were formed. This resulted in a higher cell density. As the acidity of the dough was still appropriate, a high number of cells were formed during fermentation. Comparing the dough rheology and bread texture, the differences in stiffness between the Ref wheat dough and pomace-containing dough were reduced after simulated baking, as well as the differences in bread firmness being less pronounced than the differences in dough resistance and extensibility. In total, analyzing the dough with rheology, combining frequency and temperature sweeps, can be considered as useful for predicting product handling and bread characteristics. 
Table 3. Bread texture as affected by wheat flour replacement.

\begin{tabular}{|c|c|c|c|c|}
\hline Sample ${ }^{1}$ & $\begin{array}{l}\text { Crust Firmness } \\
\text { (N) }(n=32)^{2}\end{array}$ & $\begin{array}{l}\text { Crumb Firmness } \\
\text { (N) }(n=16)^{3}\end{array}$ & $\begin{array}{c}\text { Crumb Cell } \\
\text { Density (cells/cm²) } \\
(n=4)^{2}\end{array}$ & $\begin{array}{l}\text { Total Cell Area } \\
\left(\mathrm{mm}^{2} / 100 \mathrm{~mm}^{2}\right) \\
(n=4)^{2}\end{array}$ \\
\hline Ref & $20.87 \pm 1.40^{b}$ & $5.49 \pm 1.46^{b c}$ & $26.31 \pm 4.45^{b}$ & $25.80 \pm 3.15^{c}$ \\
\hline $10 \mathrm{P}$ & $22.09 \pm 2.81^{\mathrm{ab}}$ & $5.01 \pm 0.59 b c$ & $35.97 \pm 4.31^{\mathrm{a}}$ & $33.53 \pm 2.29^{b}$ \\
\hline $10 \mathrm{Pc}$ & $22.20 \pm 3.33^{\mathrm{ab}}$ & $4.81 \pm 0.79^{c}$ & $32.75 \pm 5.53^{\mathrm{ab}}$ & $38.18 \pm 2.70^{a}$ \\
\hline $10 \mathrm{Ph}$ & $22.57 \pm 3.53^{\mathrm{ab}}$ & $6.02 \pm 0.88^{b}$ & $34.92 \pm 5.31^{\mathrm{a}}$ & $36.45 \pm 2.65^{\mathrm{ab}}$ \\
\hline WS & $23.51 \pm 3.30^{a}$ & $13.71 \pm 3.32^{\mathrm{a}}$ & $26.06 \pm 0.39^{b}$ & $32.98 \pm 2.24^{b}$ \\
\hline
\end{tabular}

${ }^{1}$ Ref, reference dough/bread; 10P, dough/bread based on $90 \%$ wheat flour and $10 \%$ pomace; 10Pc, similar to $10 \mathrm{P}$ but with pomace soaked in cold water; 10Ph, similar to 10P but with pomace soaked in boiling water; WS, dough/bread of wholegrain spelt flour. ${ }^{2}$ Mean values ( \pm standard deviation) in a column with different superscripts differ significantly $(p<0.05) .{ }^{3}$ Mean values $( \pm$ standard deviation) in this column with different superscripts differ significantly $(p<0.10)$.

Regarding appearance and color (Figure 4), the lightness of the crumb of the pomace breads decreased from 65.0 to approx. 40.0, the color saturation/chroma from 13.3 to 2.9, and the hue angle from 86.1 to 52.5 (each from Ref to 10P). The dark purple pomace color changed during baking and resulted in grayish bread crumbs. The color of the pre-hydrated samples (10Pc and 10Ph) differed to that of $10 \mathrm{P}$ below the visually just-noticeable threshold (with $\Delta \mathrm{E}^{*}=0.07$ and 0.79 , respectively). WS was characterized by $\mathrm{L}^{*}=54.7, \mathrm{C}^{*}=15.1$, and $\mathrm{h}_{\mathrm{ab}}=68.8$. Just as the color of WS varied, the flour proteins and dietary fiber of the wholegrain spelt flour acted completely differently than the mixtures of wheat flour and 10\% pomace. At present, consumers are getting accustomed, one by one, to dark-colored crumbs, such as black burger buns with natural squid ink. The appearance of blackcurrant breads is extraordinary but points to natural ingredients. Alba et al. (2020) investigated the aroma profile of blackcurrant pomace bread and detected $>100$ volatiles [10]. They attributed the terpene hydrocarbons to the berries and carbonyl compounds to lipids from their seeds [10]. Starting from this, a human sensory study would be fascinating.

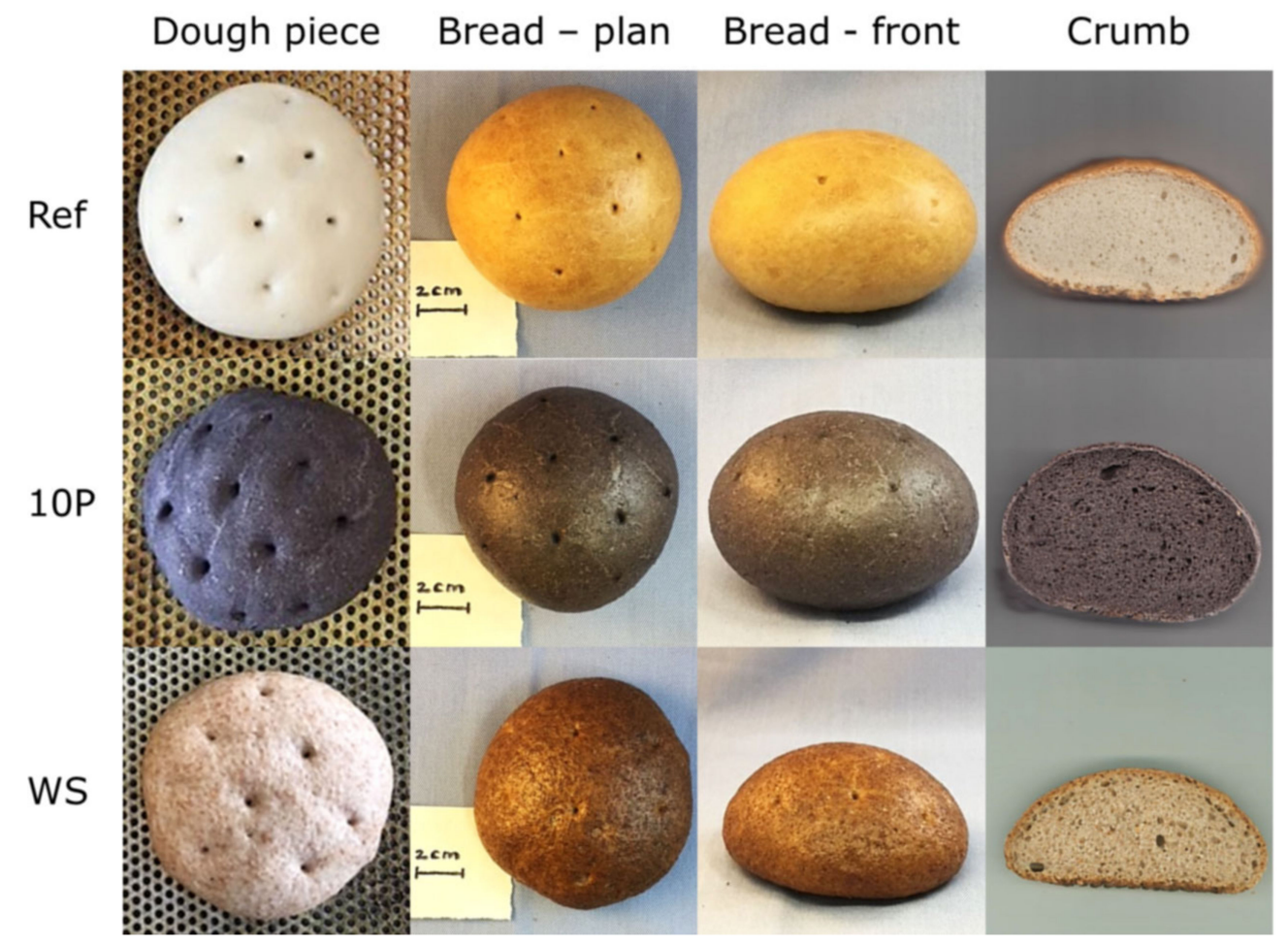

Figure 4. Appearance of dough, bread, and crumb. Ref, reference; 10P, dough/bread based on $90 \%$ wheat flour and $10 \%$ pomace; WS, wholegrain spelt flour. 


\section{Conclusions}

In a previous study on dough microstructure, it was predicted that using blackcurrant pomace up to $10 \%$ could be successful [5]. In terms of the findings obtained in the current study, this assumption can be confirmed, especially when its high water-binding capacity is considered. The hydration properties of blackcurrant pomace affected the bread-making procedure substantially. Aiming at a similar dough consistency proved to be successful. Since pomace pre-hydration increased the kneading resistance in farinograms, even more addition of water seems to be feasible. A pre-hydration in hot water improved the dough handling properties and quality parameters of the resulting bread to a larger extent than pomace soaked at room temperature. Under the conditions examined, the pre-hydration of blackcurrant pomace with boiling water for $30 \mathrm{~min}$ is favorable. The appropriate water amount can be determined by aiming at a similar kneading resistance in farinograms.

The main outcome of the study is that considering the water-binding capacity of fruit fiber is of particular relevance in bread-processing technology but also for research. A similar water content, but different hydration strategies, provoked varying dough and bread properties. As to date, the hydration of dietary fiber has often been neglected or even ignored, this is an important finding.

The presented approach may help to incorporate higher fractions of dietary fiber in bakery products. The incorporation of blackcurrant pomace is only one promising example. The enzyme activity of pre-hydrated pomace is an interesting aspect to be focused on in prospective studies.

Author Contributions: Conceptualization, H.R. and A.-M.R.; methodology and investigation, A.B. and A.-M.R.; writing-original draft preparation, A.-M.R.; writing-review and editing, H.R. and S.S.; supervision, H.R.; project administration, S.S. All authors have read and agreed to the published version of the manuscript.

Funding: The research project BERRYPOM was approved during the 2nd SUSFOOD ERA-Net call. The funding of the project, assured through the respective national partner organization, is gratefully acknowledged: Federal Ministry of Education and Research via PTJ in Germany, grant 031B0004.

Acknowledgments: We would like to thank Dresdener Mühle (ZN der PMG Premium Mühlen Gruppe $\mathrm{GmbH} \& \mathrm{Co} . \mathrm{KG}$ ) for providing the wheat flour used in this study and Döhler GmbH for supplying the blackcurrant pomace.

Conflicts of Interest: The authors declare no conflict of interest. The funders had no role in the design of the study; in the collection, analyses, or interpretation of data; in the writing of the manuscript; or in the decision to publish the results.

\section{References}

1. Alba, K.; MacNaughtan, W.; Laws, A.P.; Foster, T.J.; Campbell, G.M.; Kontogiorgos, V. Fractionation and characterisation of dietary fibre from blackcurrant pomace. Food Hydrocoll. 2018, 81, 398-408. [CrossRef]

2. Reißner, A.-M.; Al-Hamimi, S.; Quiles, A.; Schmidt, C.; Struck, S.; Hernando, I.; Turner, C.; Rohm, H. Composition and physicochemical properties of dried berry pomace: Composition and technofunctional properties of berry pomace. J. Sci. Food Agric. 2018, 99, 1284-1293. [CrossRef] [PubMed]

3. Rohm, H.; Brennan, C.; Turner, C.; Günther, E.; Campbell, G.; Hernando, I.; Struck, S.; Kontogiorgos, V. Adding value to fruit processing waste: Innovative ways to incorporate fibers from berry pomace in baked and extruded cereal-based foods-A SUSFOOD project. Foods 2015, 4, 690-697. [CrossRef] [PubMed]

4. Martins, Z.E.; Pinho, O.; Ferreira, I.M.P.L.V.O. Food industry by-products used as functional ingredients of bakery products. Trends Food Sci. Technol. 2017, 67, 106-128. [CrossRef]

5. Struck, S.; Straube, D.; Zahn, S.; Rohm, H. Interaction of wheat macromolecules and berry pomace in model dough: Rheology and microstructure. J. Food Eng. 2018, 223, 109-115. [CrossRef]

6. Guarda, A.; Rosell, C.; Benedito, C.; Galotto, M. Different hydrocolloids as bread improvers and antistaling agents. Food Hydrocoll. 2004, 18, 241-247. [CrossRef]

7. Wang, J.; Rosell, C.M.; Benedito de Barber, C. Effect of the addition of different fibres on wheat dough performance and bread quality. Food Chem. 2002, 79, 221-226. [CrossRef]

8. Lazaridou, A.; Duta, D.; Papageorgiou, M.; Belc, N.; Biliaderis, C.G. Effects of hydrocolloids on dough rheology and bread quality parameters in gluten-free formulations. J. Food Eng. 2007, 79, $1033-1047$. [CrossRef] 
9. Gómez, M.; Ronda, F.; Blanco, C.A.; Caballero, P.A.; Apesteguía, A. Effect of dietary fibre on dough rheology and bread quality. Eur. Food Res. Technol. 2003, 216, 51-56. [CrossRef]

10. Alba, K.; Rizou, T.; Paraskevopoulou, A.; Campbell, G.M.; Kontogiorgos, V. Effects of blackcurrant fibre on dough physical properties and bread quality characteristics. Food Biophys. 2020, 15, 313-322. [CrossRef]

11. Hemdane, S.; Jacobs, P.J.; Dornez, E.; Verspreet, J.; Delcour, J.A.; Courtin, C.M. Wheat (Triticum aestivum L.) bran in bread making: A critical review. Compr. Rev. Food Sci. Food Saf. 2016, 15, 28-42. [CrossRef]

12. Mildner-Szkudlarz, S.; Bajerska, J.; Zawirska-Wojtasiak, R.; Górecka, D. White grape pomace as a source of dietary fibre and polyphenols and its effect on physical and nutraceutical characteristics of wheat biscuits: Addition of white grape pomace to wheat biscuits. J. Sci. Food Agric. 2013, 93, 389-395. [CrossRef] [PubMed]

13. Schmidt, C.; Geweke, I.; Struck, S.; Zahn, S.; Rohm, H. Blackcurrant pomace from juice processing as partial flour substitute in savoury crackers: Dough characteristics and product properties. Int. J. Food Sci. Technol. 2018, 53, 237-245. [CrossRef]

14. Freund, W. Handbuch Backwaren-Technologie, 4th ed.; Behr's Verlag: Hamburg, Germany, 2003.

15. ICC. Determination of the Moisture Content of Cereals and Cereal Products (Practical Method); Standard 110/1; International Association for Cereal Science and Technology: Vienna, Austria, 1976.

16. ICC. Method for Using the Brabender Farinograph; Standard 115/1; International Association for Cereal Science and Technology: Vienna, Austria, 1992.

17. Verheyen, C.; Jekle, M.; Becker, T. Effects of Saccharomyces cerevisiae on the structural kinetics of wheat dough during fermentation. LWT-Food Sci. Technol. 2014, 58, 194-202. [CrossRef]

18. Balestra, F. Empirical and Fundamental Mechanical Tests in the Evaluation of Dough and Bread Rheological Properties. Ph.D. Thesis, Universita di Bologna, Bologna, Italy, 2014.

19. AACC. Guidelines for Measurement of Volume by Rapeseed Displacement. AACC Method 10-05.01. In Approved Methods of Analysis, 11th ed.; AACC International: St. Paul, MN, USA, 2009.

20. AACC. Staleness/Texture. AACC Method 74-09.01. In Approved Methods of Analysis, 11th ed.; AACC International: ST. Paul, MN, USA, 2009.

21. Rohm, H.; Jaros, D. Colour of hard cheese: 1 . Description of colour properties and effects of maturation. Z. Lebensm. Unters. Forsch. 1996, 203, 241-244. [CrossRef]

22. Frakolaki, G.; Giannou, V.; Topakas, E.; Tzia, C. Chemical characterization and breadmaking potential of spelt versus wheat flour. J. Cereal Sci. 2018, 79, 50-56. [CrossRef]

23. Peressini, D.; Sensidoni, A. Effect of soluble dietary fibre addition on rheological and breadmaking properties of wheat doughs. J. Cereal Sci. 2009, 49, 190-201. [CrossRef]

24. Dreese, P.C.; Faubion, J.M.; Hoseney, R.C. Dynamic rheological properties of flour, gluten, and gluten-starch doughs. I. Temperature-dependent changes during heating. Cereal Chem. 1988, 65, 348-353.

25. Rosell, C.; Rojas, J.; Benedito de Barber, C. Influence of hydrocolloids on dough rheology and bread quality. Food Hydrocoll. 2001, 15, 75-81. [CrossRef]

26. Sudha, M.L.; Baskaran, V.; Leelavathi, K. Apple pomace as a source of dietary fiber and polyphenols and its effect on the rheological characteristics and cake making. Food Chem. 2007, 104, 686-692. [CrossRef]

27. Jekle, M.; Becker, T. Dough microstructure: Novel analysis by quantification using confocal laser scanning microscopy. Food Res. Int. 2011, 44, 984-991. [CrossRef]

28. Belghith Fendri, L.; Chaari, F.; Maaloul, M.; Kallel, F.; Abdelkafi, L.; Ellouz Chaabouni, S.; Ghribi-Aydi, D. Wheat bread enrichment by pea and broad bean pods fibers: Effect on dough rheology and bread quality. LWT-Food Sci. Technol. 2016, 73, 584-591. [CrossRef]

29. Cauvain, S. Functional Ingredients. In Technology of Breadmaking, 3rd ed.; Springer International Publishing: Cham, Switzerland, 2015; p. 90.

30. Rathnayake, H.A.; Navaratne, S.B.; Navaratne, C.M. Porous crumb structure of leavened baked products. Int. J. Food Sci. 2018, 8187318. [CrossRef]

31. Karnopp, A.R.; Figueroa, A.M.; Los, P.R.; Teles, J.C.; Simões, D.R.S.; Barana, A.C.; Kubiaki, F.T.; de Oliveira, J.G.B.; Granato, D. Effects of whole-wheat flour and bordeaux grape pomace (Vitis labrusca L.) on the sensory, physicochemical and functional properties of cookies. Food Sci. Technol. Camp. 2015, 35, 750-756. [CrossRef]

32. Kotoki, D.; Deka, S.C. Baking loss of bread with special emphasis on increasing water holding capacity. J. Food Sci. Technol. 2010, 47, 128-131. [CrossRef]

33. Kučerová, J.; Šottníková, V.; Nedomová, Š. Influence of dietary fibre addition on the rheological and sensory properties of dough and bakery products. Czech J. Food Sci. 2013, 31, 340-346. [CrossRef] 
34. Tańska, M.; Zadernowski, R.; Konpka, I. The quality of wheat bread supplemented with dried carrot pomace. Pol. J. Nat. Sci. 2007, 27, 126-136. [CrossRef]

35. Skendi, A.; Biliaderis, C.G.; Papageorgiou, M.; Izydorczyk, M.S. Effects of two barley $\beta$-glucan isolates on wheat flour dough and bread properties. Food Chem. 2010, 119, 1159-1167. [CrossRef]

36. Holmes, J.T.; Hoseney, R.C. Chemical leavening: Effect of $\mathrm{pH}$ and certain ions on breadmaking properties. Cereal Chem. 1987, 64, 343-348.

Publisher's Note: MDPI stays neutral with regard to jurisdictional claims in published maps and institutional affiliations.

(C) 2020 by the authors. Licensee MDPI, Basel, Switzerland. This article is an open access article distributed under the terms and conditions of the Creative Commons Attribution (CC BY) license (http://creativecommons.org/licenses/by/4.0/). 